\title{
HMGB1 enhances mechanical stress-induced cardiomyocyte hypertrophy in vitro via the RAGE/ERK1/2 signaling pathway
}

\author{
LEI ZHANG $^{1 *}$, XUE YANG $^{1 *}$, GUOLIANG JIANG $^{1 *}$, YING YU $^{2}$, JIAN WU $^{1}$, YANGANG SU $^{1}$, \\ AIJUN SUN ${ }^{1}$, YUNZENG ZOU ${ }^{1}$, HONG JIANG ${ }^{1}$ and JUNBO GE ${ }^{1}$ \\ ${ }^{1}$ Department of Cardiology, Shanghai Institute of Cardiovascular Diseases, and ${ }^{2}$ Department of General Practice, \\ Zhongshan Hospital, Shanghai Medical College of Fudan University, Shanghai 200032, P.R. China
}

Received January 7, 2019; Accepted June 26, 2019

DOI: $10.3892 / \mathrm{ijmm} .2019 .4276$

\begin{abstract}
Pressure overload-induced cardiac hypertrophy is associated with a complex spectrum of pathophysiological mechanisms, including the inflammation response. High mobility group box-1 (HMGB1), a pro-inflammatory cytokine, is not only increased in myocardium under pressure overload, but also exacerbates pressure overload-induced cardiac hypertrophy and dysfunction; however, the underlying mechanisms have remained elusive. In the present study, cultured cardiomyocytes were stimulated by mechanical stress and/or HMGB1 for various durations to examine the role of HMGB1 in cardiomyocyte hypertrophy, and to detect the expression of receptor for advanced glycation end products (RAGE), toll-like receptor 4 (TLR-4) and the activation status of mitogen-activated protein kinases (MAPKs) and Janus kinase 2 (JAK2)/STAT3. The results indicated that HMGB1 aggravated mechanical stress-induced cardiomyocyte hypertrophy. Furthermore, mechanical stress and HMGB1 stimulation activated extracellular signal-regulated kinase $1 / 2$ (ERK1/2), P38 and JAK2/STAT3 signaling in cardiomyocytes, but an additive effect of the combined stimuli was only observed on the activation of ERK1/2. In addition, mechanical stress caused a prompt upregulation of the expression of RAGE and TLR-4 in cardiomyocytes, while the activation of ERK1/2 by HMGB1 was inhibited by blockage of RAGE, but not by blockage of TLR-4. In summary, the present results indicated that extracellular HMGB1 enhanced mechanical stress-induced cardiomyocyte hypertrophy in vitro, at least partially via the RAGE/ERK1/2 signaling pathway.
\end{abstract}

Correspondence to: Dr Hong Jiang, Department of Cardiology, Shanghai Institute of Cardiovascular Diseases, Zhongshan Hospital, Shanghai Medical College of Fudan University, 180 Fenglin Road, Shanghai 200032, P.R. China

E-mail: jiang.hong@zs-hospital.sh.cn

${ }^{*}$ Contributed equally

Key words: cardiomyocyte hypertrophy, high mobility group box-1, mechanical stress, receptor for advanced glycation end products, extracellular signal-regulated kinase

\section{Introduction}

Pathological cardiac hypertrophy, which is accompanied by increased cardiomyocyte death, fibrotic remodeling and cardiac dysfunction, is generally considered to be an independent risk factor of heart failure $(1,2)$. It is well established that not only mechanical stress, but also inflammatory factors are involved in pressure overload-induced pathological hypertrophy (3-5). High mobility group box 1 (HMGB1), which has diverse biological roles, is a highly conserved, ubiquitous protein in various types of cells. It has been reported that HMGB1 exists in the nucleus under physiological conditions, while extracellular HMGB1 functions as a pro-inflammatory cytokine when released by activated inflammatory cells or necrotic cells $(6,7)$. A recent study by our group indicated that cardiac HMGB1 expression is increased in mice with transverse aortic constriction (TAC), and it is involved in cardiac hypertrophy under pressure overload (8); however, the underlying mechanisms have remained to be fully elucidated.

Cardiac hypertrophy is generally considered to be a highly complex process, which is mediated by multiple signaling pathways, including intracellular calcium, cyclic guanosine monophosphate/protein kinase $\mathrm{G}$, protein kinase $\mathrm{C}$, mitogen-activated protein kinase (MAPK) and Janus kinase (JAK)/STAT signaling pathways $(9,10)$. It is accepted that activation of ERK, JNK and p38 are all closely associated with this process (11-13). In addition, JAK (mainly JAK2) and its effector, STAT (particularly STAT3), were reported to be significantly increased in the process of cardiac hypertrophy (14).

Furthermore, it has been indicated that ischemia-reperfusion injury increases the expression of HMGB1 in cardiac tissue, which, in turn, aggravates cardiac ischemia-reperfusion injury by activating JNK, ERK and nuclear factor (NF)-кB (15). In addition, upregulated interleukin (IL)-6 induced by HMGB1 triggers cardiomyocyte hypertrophy via the JAK/STAT signaling pathway $(16,17)$. Considering this together with the fact that HMGB1 functions as an inflammatory factor, mainly through acting on the receptor for advanced glycation end products (RAGE) and toll-like receptor (TLR)-2 and TLR-4 (18-20), it appears plausible that the above mentioned receptors and signaling pathways may be involved in the effect of HMGB1 on cardiac hypertrophy 
under pressure overload. In this light, the aim of the present study was to examine the potential additive effects of HMGB1 and mechanical stress on these signaling pathways in the process of cardiac hypertrophy in vitro.

\section{Materials and methods}

Cell culture. Inhalation anesthesia was performed on one- or two-day-old Sprague Dawley rat pups with 2\% isoflurane, and anesthetic depth was assessed with reaction to nociceptive stimulus $(21,22)$. After the reactions were lost, pups were sterilized locally with $75 \%$ ethanol, the chest was opened quickly along the sternum to harvest the heart, and then primary cultures of rat ventricular myocytes were obtained as described previously $(23,24)$. The experiment protocols were approved by the Institutional Animal Care and Use Committee of Fudan University (Shanghai, China).

H9c2 cells were purchased from Shanghai Institutes for Biological Sciences. Cells were incubated in low-glucose Dulbecco's modified Eagle's medium (DMEM; Gibco; Thermo Fisher Scientific, Inc.) supplemented with $10 \%$ (v/v) fetal bovine serum (FBS; Gibco; Thermo Fisher Scientific, Inc.), $100 \mathrm{U} / \mathrm{ml}$ each of penicillin and streptomycin, and $20 \mathrm{mM}$ HEPES (pH 7.2) at $37^{\circ} \mathrm{C}$ in humidified air with $5 \% \mathrm{CO}_{2}$. Confluent monolayers exhibiting spontaneous contractions were developed in culture within 2 days.

Plasmid transfection. $\mathrm{H} 9 \mathrm{c} 2$ cells were transfected with green fluorescence protein (GFP) plasmid (4 $\mu \mathrm{g}$; Takara Biotechnology Co., Ltd.) using Lipofectamine ${ }^{\mathrm{TM}} 2000$ transfection reagent (Invitrogen; Thermo Fisher Scientific, Inc.) according to the manufacturer's instructions. The efficacy of transfection was $>80 \%$, as determined by fluorescence microscopy (magnification, x100). All cultures were transferred to serum-free conditions for $48 \mathrm{~h}$ prior to stimulation experiments.

Mechanical stretch and HMGB1 stimulation. Based on a previous study by our group (8), the cardiomyocytes were cultured in DMEM with 10\% FBS and then incubated under serum and antibiotic-free conditions in silicon-based plates pre-coated with collagen for $48 \mathrm{~h}$ prior to mechanical stretch. Uniaxial strain was applied by stretching the silicone plate in the frame by $20 \%$ in length along the plate $(25,26)$. Cultured cardiomyocytes were stimulated by mechanical stress (stretched mechanically to $120 \%$ ) (27) and/or with $100 \mathrm{ng} / \mathrm{ml}$ recombinant HMGB1 (HMGBiotech) (8) for 5, 10 or 30 min, or 1, 2, 4, 8, 12 or $24 \mathrm{~h}$. In other experiments as indicated, RAGE and TLR-4 were blocked by using specific neutralizing antibodies to RAGE (20 $\mu \mathrm{g} / \mathrm{ml}$; sc-365154; Santa Cruz Biotechnology, Inc.) (28) and to TLR-4 (20 $\mu \mathrm{g} / \mathrm{ml}$; ab137582; Abcam) (29), respectively, as a 30 min pretreatment prior to HMGB1 stimulation.

Cell surface area measurements. H9c2 cells transfected with GFP plasmid (as aforementioned) were used for the cell surface area measurement experiments. Positive staining was observed under a fluorescence microscope (magnification, x100; Olympus Corporation). The area of the cell was assessed using the AxioVision 4.5 (Zeiss GmbH) software (30) and calculated as the mean of $\sim 100$ cells from randomly selected fields.
Western blot analysis. The total cellular proteins were extracted at the corresponding time-points with radioimmunoprecipitation assay lysis buffer (Beyotime Institute of Biotechnology). The protein concentration was detected using the Pierce bicinchoninic acid protein assay kit (Thermo Fisher Scientific, Inc.). The extracted proteins $(30 \mu \mathrm{g})$ were boiled in loading buffer for $10 \mathrm{~min}$, separated by $12 \%$ SDS-PAGE and transferred to a nitrocellulose membrane (Thermo Fisher Scientific, Inc.). The membrane was incubated at room temperature for $2 \mathrm{~h}$ in $5 \%$ FBS to block non-specific binding sites, and then incubated overnight at $4^{\circ} \mathrm{C}$ with the primary antibodies. The antibodies used were (1:1,000 dilution; Cell Signaling Technology, Inc.): ERK1/2 (cat. no. 4695), phosphorylated (p-) ERK1/2 (cat. no. 9101), P38 (cat. no. 9212), p-P38 (cat. no. 4511), JAK2 (cat. no. 3230), p-JAK2 (cat. no. 3771), STAT3 (cat. no. 4904), p-STAT3 (cat. no. 9145), GAPDH (cat. no. 5174), and $\beta$-actin (cat. no. 4970). The primary antibody targeting GFP was from Santa Cruz Biotechnology, Inc. (cat. no. sc-5384; 1:1,000). Subsequently, the membrane was washed for $10 \mathrm{~min}$ with Tris-buffered saline containing Tween-20 (TBST) three times and then incubated with a horseradish peroxide (HRP)-conjugated secondary antibody (1:10,000; Cell Signaling Technology, Inc.; anti-rabbit cat. no. 7074 or anti-mouse cat. no. 7076) at room temperature for $2 \mathrm{~h}$. Finally, the membrane was washed for $10 \mathrm{~min}$ with TBST buffer three times, exposed using a LAS-3000 imaging system (FujiFilm Holding Corporation) and the expression of the corresponding proteins was determined using the Quantity One software (v4.6.6; Bio-Rad Laboratories, Inc.).

Statistical analysis. Values are expressed as the mean \pm standard error from three individual experiments. One-way analysis of variance was applied for comparison between groups. $\mathrm{P}<0.05$ was considered to indicate a statistically significant difference. Statistical analysis was performed using the SPSS 16.0 statistical package (SPSS, Inc.).

\section{Results}

HMGB1 enhances mechanical stress-induced cardiomyocyte hypertrophy. To examine the effect of HMGB1 on cardiomyocyte hypertrophy under mechanical stress, $\mathrm{H} 9 \mathrm{C} 2$ cells were transfected with GFP plasmid, and $48 \mathrm{~h}$ later, they were stimulated with HMGB1 and/or mechanical stretch. Fig. 1A shows that the transfection of GFP was successful. Compared with that of the control cells, the cell surface area was significantly increased in the cells treated by mechanical stretch for $24 \mathrm{~h}(\mathrm{P}<0.01$; Fig. 1B and $\mathrm{C})$, but not in those with HMGB1 stimulation alone. Notably, HMGB1 stimulation combined with mechanical stretch further aggravated the mechanical stress-induced cardiomyocyte hypertrophy $(\mathrm{P}<0.05$; Fig. 1B and $\mathrm{C})$.

Mechanical stress and HMGB1 activate MAPKs in cardiomyocytes. To further investigate the mechanisms of cardiomyocyte hypertrophy induced by mechanical stress and HMGB1 stimulation, the activation status of MAPKs under these conditions was detected. Primary rat neonatal cardiomyocytes were subjected to mechanical stretch and/or HMGB1 stimulation for 0, 5, 10, 30 and $60 \mathrm{~min}$. Western blot analysis results indicated that the levels of p-ERK1/2 were significantly upregulated in cardiomyocytes 
A
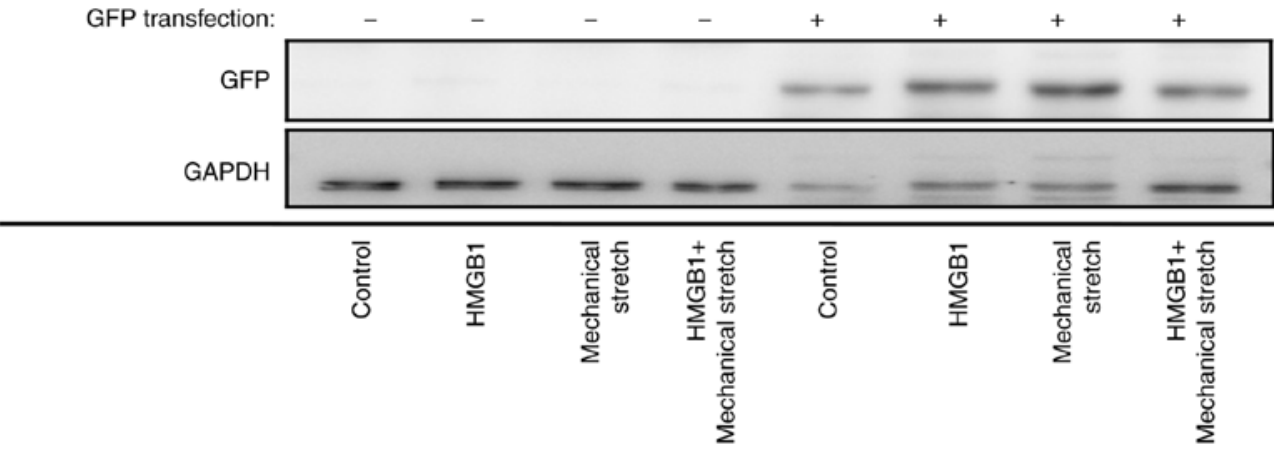

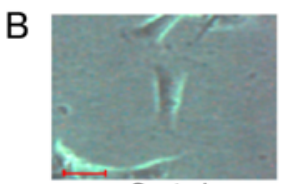

Control

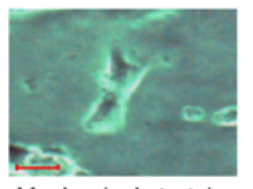

Mechanical stretch

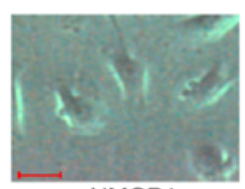

HMGB1

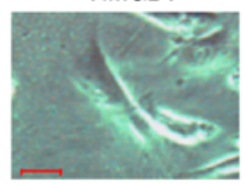

HMGB1+ Mechanical stretch

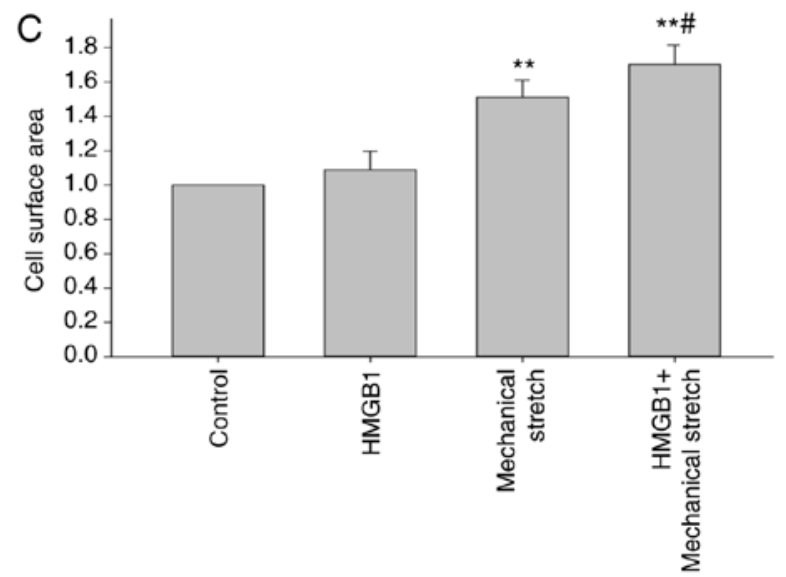

Figure 1. HMGB1 enhances mechanical stress-induced cardiomyocyte hypertrophy. H9c2 cells were transfected with a GFP-expressing plasmid, and 48 h later, they were stimulated with $100 \mathrm{ng} / \mathrm{ml} \mathrm{HMGB1}$ and/or mechanical stretch for $24 \mathrm{~h}$. (A) Western blot analysis confirmed successful GFP transfection in H9c2 cells. (B) Positive staining was observed under a fluorescence microscope (scale bar, $10 \mu \mathrm{m}$ ). (C) Quantification of cell surface area. Values are expressed as the mean \pm standard error from three independent experiments. ${ }^{* *} \mathrm{P}<0.01$ vs. control; ${ }^{\#} \mathrm{P}<0.05$ vs. mechanical stretch. HMGB1, high mobility group box-1; GFP, green fluorescence protein.

treated with mechanical stretch (from 5 min onwards) or HMGB1 (from 30 min onwards), in a time-dependent manner $(\mathrm{P}<0.05)$. Of note, an additive effect of mechanical stretch and HMGB1 stimulation on the activation of ERK1/2 was observed at $30 \mathrm{~min}$, resulting in a greater increase in p-ERK1/2 compared with that achieved by mechanical stretch or HMGB1 stimulation alone ( $\mathrm{P}<0.05$; Fig. 2A and $\mathrm{B})$. Furthermore, the levels of p-P38 in cardiomyocytes were increased by mechanical stretch and by HMGB1 stimulation $(\mathrm{P}<0.05)$, but the combined treatment had no additive effect (Fig. 2C and D).

Mechanical stress and HMGB1 activate JAK2/STAT3 in cardiomyocytes. As another important signaling pathway involved in cell hypertrophy, the activation of JAK2/STAT3 was also assessed. It was revealed that the levels of p-JAK2 were upregulated by mechanical stretch and by HMGB1 stimulation, while the former but not the latter maintained the activation of JAK2 ( $\mathrm{P}<0.05$; Fig. 3A and B). Furthermore, the levels of p-STAT3 increased from 30 min onwards in the stretch group and from 10 min onwards in the HMGB1 group $(\mathrm{P}<0.05$; Fig. 3C and D). However, no additive effects between mechanical stress and HMGB1 simulation were observed on the activation of JAK2 and STAT3.

Mechanical stress induces the expression of RAGE and TLR-4 in cardiomyocytes. A previous study by our group indicated that cardiac HMGB1 was not only increased but also activated under pressure overload (8). In the present study, the effects of mechanical stretch on the expression of RAGE and TLR-4, two receptors of HMGB1, were explored in cardiomyocytes. The results suggested that the protein expression levels of RAGE were significantly increased at 8 and $12 \mathrm{~h}(\mathrm{P}<0.05$; Fig. 4A and B), while TLR-4 expression was significantly increased at 4 and $8 \mathrm{~h}$ of stretch $(\mathrm{P}<0.05$; Fig. $4 \mathrm{C}$ and $\mathrm{D})$. These results indicated that RAGE and TLR-4 may mediate the additive effect of HMGB1 on pressure overload-induced cardiomyocyte hypertrophy.

Roles of RAGE and TLR-4 receptors in the activation of signaling pathways by HMGB1. HMGB1 alone had no influence in cardiac hypertrophy; however, it aggravated pressure/mechanical stress-induced hypertrophy (Fig. 1). To further explore the mechanism underlying this function of HMGB1, the present study aimed to investigate the role of target receptors of HMGB1 in cardiac hypertrophy. Primary cardiomyocytes were treated with HMGB1 for $30 \mathrm{~min}$, at which point the levels of p-ERK1/2 were significantly increased (Fig. 5A and B). Blocking the RAGE receptor significantly inhibited ERK1/2 activation $(\mathrm{P}<0.05$; Fig. $5 \mathrm{~A}$ and $\mathrm{B})$, while no effect was observed following blocking of the TLR-4 receptor (Fig. 5A and B). By contrast, the HMGB1-induced increase in the levels of p-JAK2 (Fig. 5C and D) and p-STAT3 (Fig. 5E and F) was not affected by either RAGE or TLR-4 receptor inhibition. These results indicated that RAGE/ERK1/2 may be one of the signaling pathways mediating HMGB1-stimulated hypertrophy under mechanical stress. 

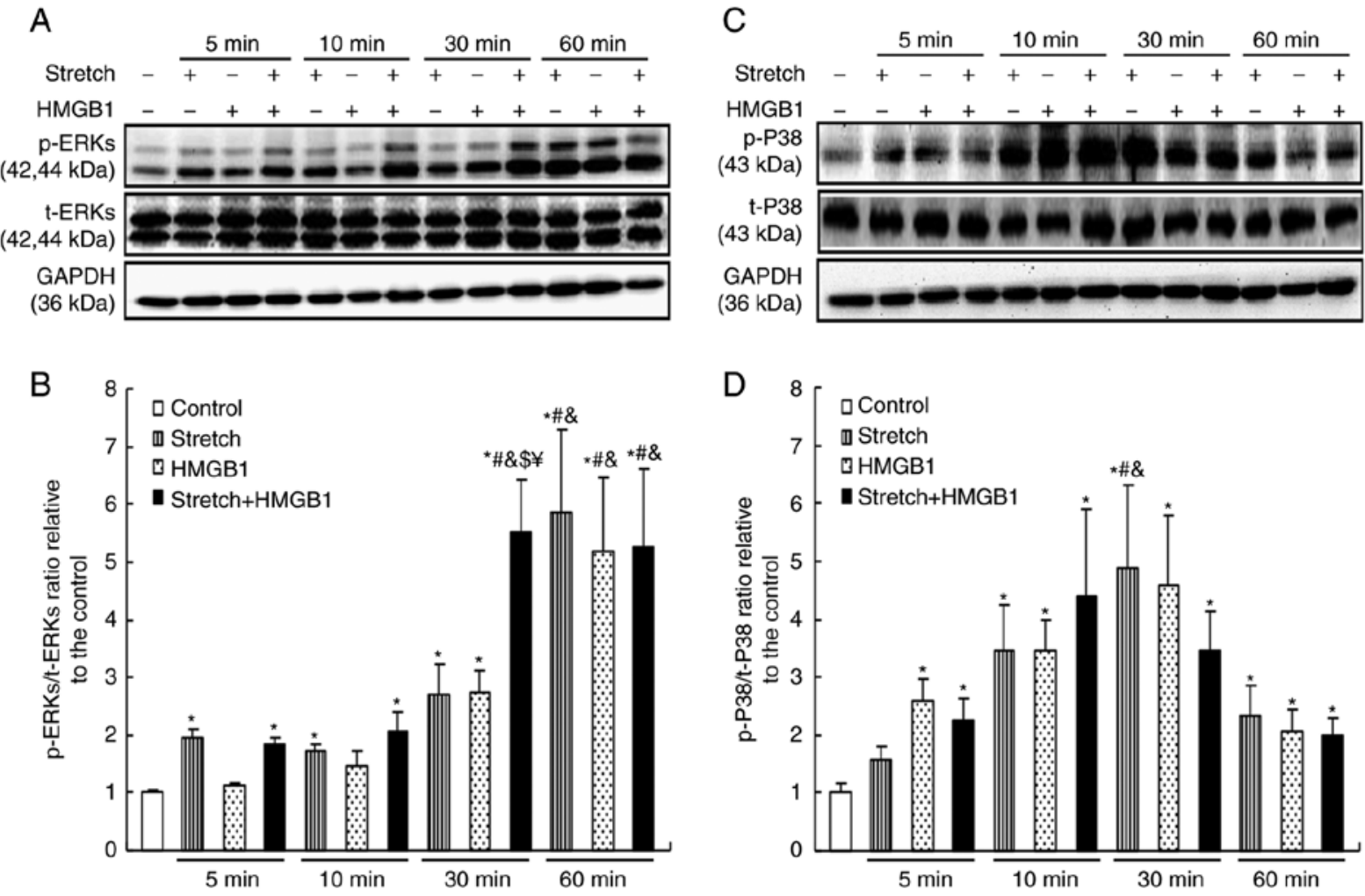

Figure 2. Mechanical stress and HMGB1 stimulation activate mitogen-activated protein kinase signaling in cardiomyocytes. Neonatal rat cardiomyocytes were stimulated with $100 \mathrm{ng} / \mathrm{ml} \mathrm{HMGB1}$ and/or mechanical stretch for 5, 10 or $30 \mathrm{~min}$, or $1 \mathrm{~h}$. Protein expression levels were then analyzed by western blotting. (A) Representative images and (B) quantification of p-ERKs and t-ERKs levels. (C) Representative images and (D) quantification of p-P38 and t-P38 levels. Values are expressed as the mean \pm standard error from three independent experiments. "P<0.05 vs. control; ${ }^{\#} \mathrm{P}<0.05$ vs. groups with the same stimuli at 5 min; ${ }^{\&} \mathrm{P}<0.05$ vs. groups with the same stimuli at $10 \mathrm{~min}$; ${ }^{\$} \mathrm{P}<0.05$ vs. mechanical stretch treatment alone for $30 \mathrm{~min} .{ }^{ } \mathrm{P}<0.05$ vs. HMGB1 alone for 30 min. HMGB1, high mobility group box-1; p-, phosphorylated; ERK, extracellular signal-regulated kinase; t-, total.
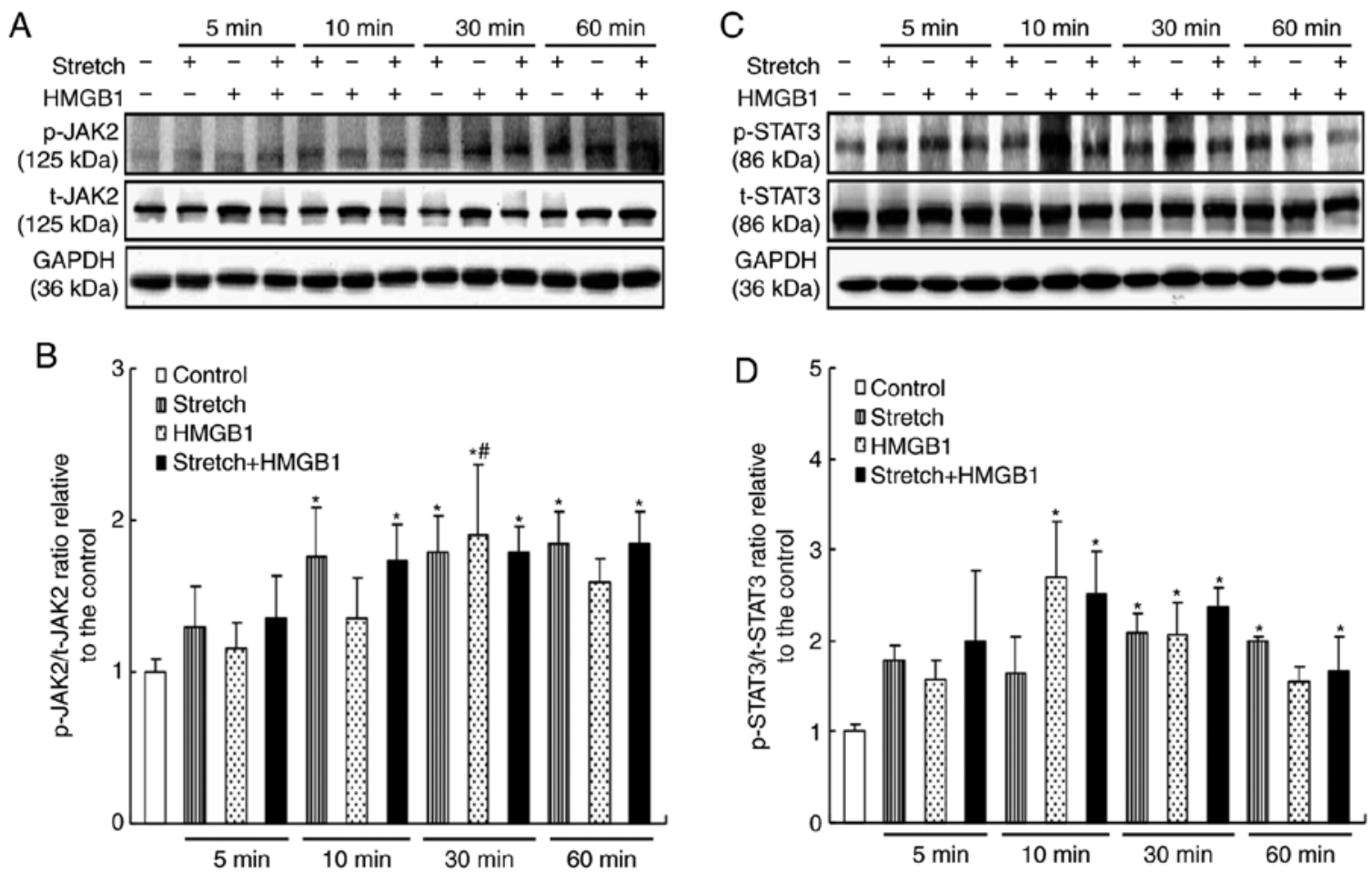

Figure 3. Mechanical stress and HMGB1 stimulation activate JAK2/STAT3 in cardiomyocytes. HMGB1 (100 ng/ml) and/or mechanical stress were applied to cultured cardiomyocytes for 5, 10,30 or $60 \mathrm{~min}$. Protein expression levels were then analyzed by western blotting. (A) Representative images and (B) quantification of p-JAK2 and t-JAK2 levels. (C) Representative images and (D) quantification of p-STAT3 and t-STAT3 levels. Values are expressed as the mean \pm standard error from three independent experiments. ${ }^{*} \mathrm{P}<0.05$ vs. control; ${ }^{*} \mathrm{P}<0.05$ vs. groups with the same stimuli at 5 min. HMGB1, high mobility group box-1; JAK2, Janus kinase 2; p-, phosphorylated; t-, total. 

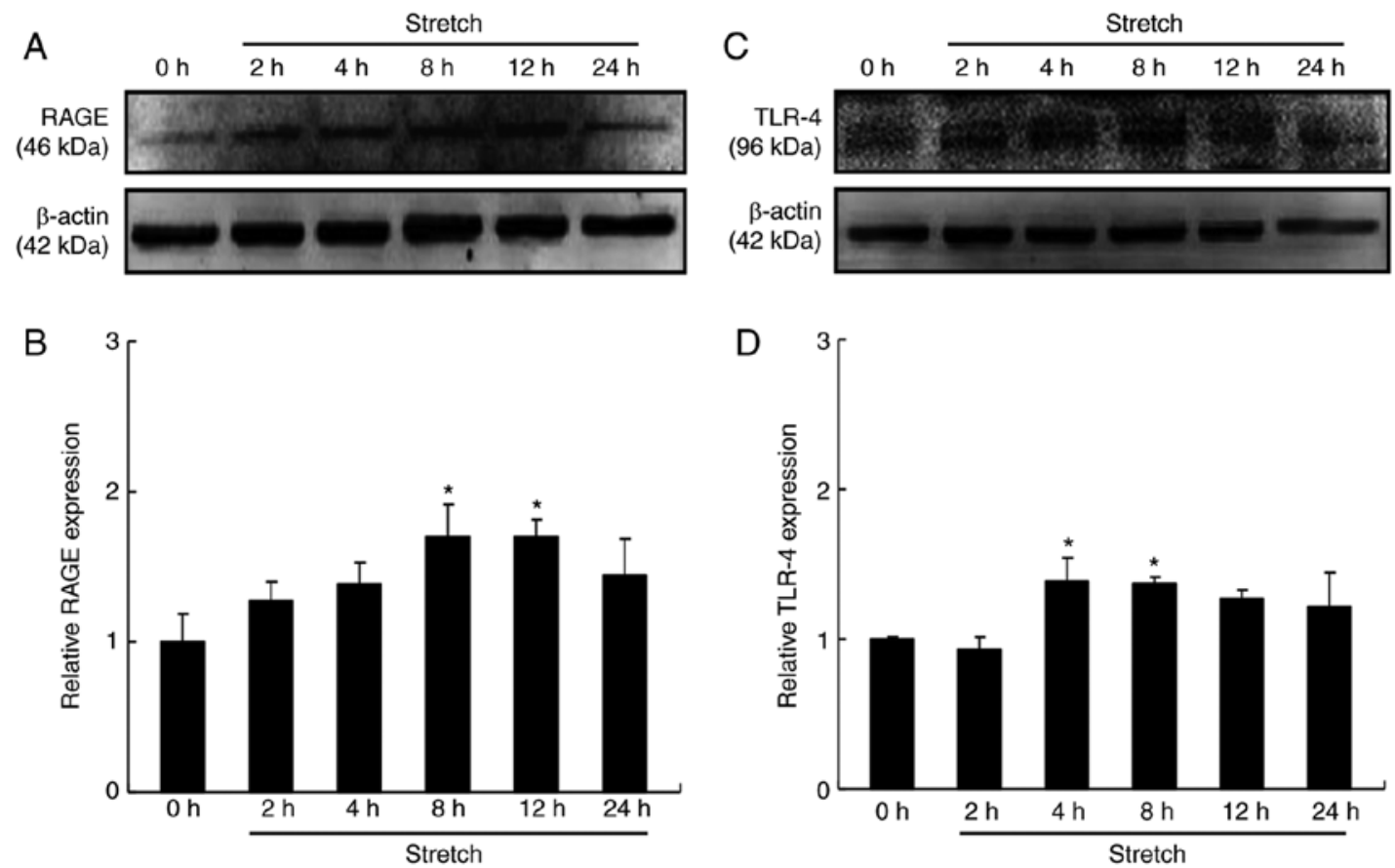

Figure 4. Mechanical stress induces the expression of RAGE and TLR-4 in cardiomyocytes. Cultured cardiomyocytes were stimulated with mechanical stress for 2, 4, 8, 12 and $24 \mathrm{~h}$, respectively. Protein expression levels were then analyzed by western blotting. (A) Representative images and (B) quantification of RAGE levels. (C) Representative images and (D) quantification of TLR-4 levels. Values are expressed as the mean \pm standard error from three independent experiments. ${ }^{*} \mathrm{P}<0.05$ vs. control. RAGE, receptor for advanced glycation end products; TLR-4, toll-like receptor 4.

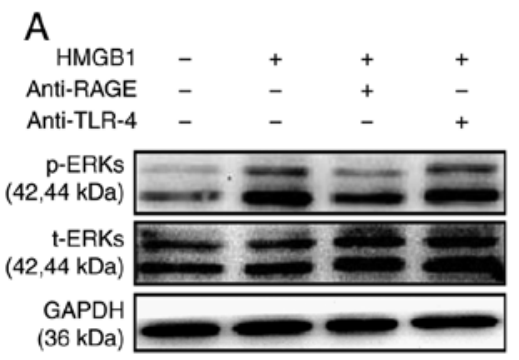

B

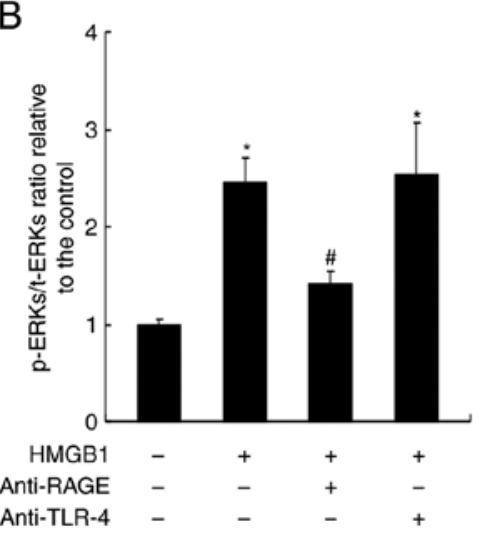

C

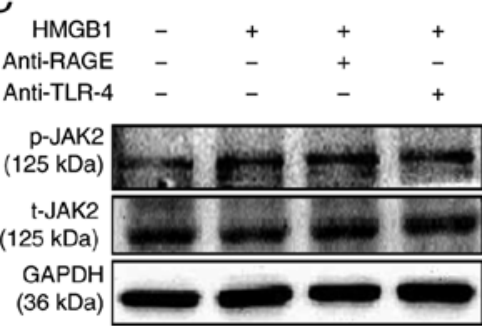

D

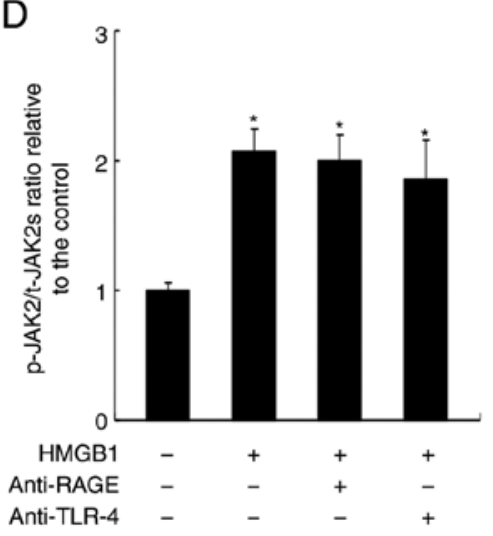

$\mathrm{E}$

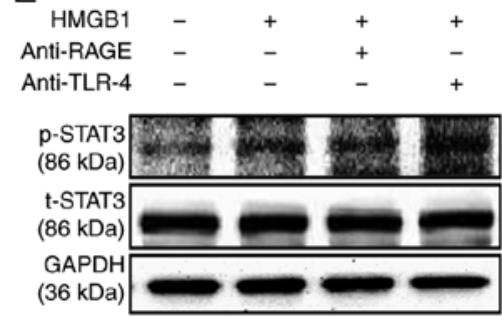

$\mathrm{F}$

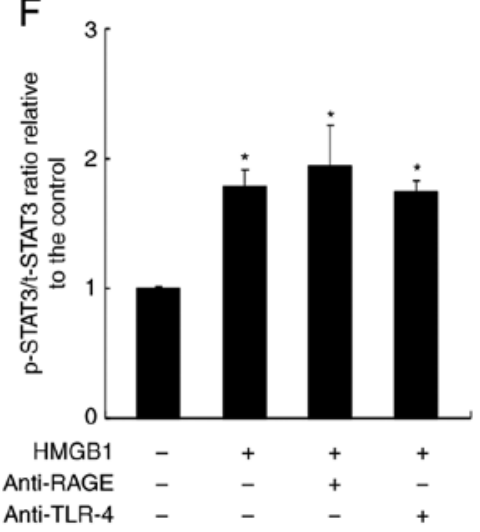

Figure 5. Roles of RAGE and TLR-4 receptors in the activation of signaling pathways by HMGB1. Cardiomyocytes were pretreated either a RAGE-neutralizing antibody $(20 \mu \mathrm{g} / \mathrm{ml})$ or a TLR-4-neutralizing antibody $(20 \mu \mathrm{g} / \mathrm{ml})$ for $30 \mathrm{~min}$, and stimulated with HMGB1 for a further 30 min. Cells were then analyzed by western blotting for the activation of (A and B) ERKs, (C and D) JAK2 and (E and F) STAT3. Values are expressed as the mean \pm standard error from three independent experiments. "P $<0.05$ vs. control; " $\mathrm{P}<0.05$ vs. HMGB1 group. RAGE, receptor for advanced glycation end products; TLR-4, toll-like receptor 4; HMGB1, high mobility group box-1; ERK, extracellular signal-regulated kinase; JAK2, Janus kinase 2; p-, phosphorylated; t-, total.

\section{Discussion}

Recent work by our group has demonstrated that cardiac HMGB1 expression was increased under pressure overload, and exogenous HMGB1 exacerbated TAC-induced cardiac hypertrophy and dysfunction (8). Consistent with a previous study (31), the present study indicated that HMGB1 aggravated mechanical stress-induced cardiomyocyte hypertrophy, but 
failed to induce such phenotype change alone. Furthermore, mechanical stress and HMGB1 were able to activate not only MAPKs but also JAK/STAT signaling in cardiomyocytes, and these two stimuli had an additive effect on activating ERK1/2, indicating that ERK1/2 may be the pivotal downstream molecule of HMGB1, which aggravates cell hypertrophy induced by mechanical stress. It was further indicated that mechanical stress directly upregulated the expression of HMGB1 receptors (RAGE/TLR-4) in cardiomyocytes, while blocking of RAGE, but not of TLR-4, inhibited the activation of ERK1/2 by HMGB1, suggesting that extracellular HMGB1 enhanced mechanical stretch-induced cardiomyocyte hypertrophy, at least partially, via activating the RAGE/ERK signaling pathway in vitro.

Primary rat neonatal cardiomyocytes were used in the present study to explore the molecular mechanisms and signaling pathways involved in cardiac hypertrophy; however, it was not feasible to use these primary cells in the phenotype assays, because they exhibited very low transfection efficiency and were not efficiently labeled with GFP. Owing to the good performance of $\mathrm{H} 9 \mathrm{c} 2$ cells in transfection with GFP-expressing plasmids, these cells were used instead to detect the phenotype changes of myocardial hypertrophy in Fig. 1. H9c2 is a rat embryonic cardiac myoblast cell line, which is employed widely as an in vitro cardiomyocyte model to explore molecular mechanisms $(4,32,33)$ and phenotype changes (34-37) of myocardial hypertrophy. In our previous study, it was demonstrated that exogenous HMGB1 aggravated pressure overload-induced cardiomyocyte enlargement in vivo (8). The present study confirmed the effect of exogenous HMGB1 on mechanical stress-induced cardiomyocyte enlargement in vitro. A limitation of the present study was that cell size was measured as the only indication of hypertrophy, and other parameters, such as relative gene expression, were not evaluated; further studies will be needed to fully elucidate the role and effect of HMGB1 in cardiac hypertrophy.

The pathological process of cardiac hypertrophy is associated with a complex spectrum of pathophysiological changes at the molecular level, which may be divided into three parts: Accumulation of extracellular pro-hypertrophic factors, intracellular signal-transduction circuits and alterations of nuclear gene transcription and protein translation, which ultimately induce hypertrophic phenotypes in cardiomyocytes $(38,39)$. Diverse signaling pathways were proved to be essential for physiological hypertrophy and dysregulation of these pathways promoted pathological hypertrophy. MAPK signaling has an important role in the development and progression of cardiac hypertrophy. Extracellular stimulations may recruit and activate MAPKs through membrane proteins, including cell membrane tyrosine kinase receptor, $\mathrm{G}$ protein coupling receptor and ion channel coupling receptor $(11,40)$. Phosphorylated MAPKs subsequently activate downstream substrates involved in cardiac hypertrophy, including c-Jun, activated transcription factor 2 and cardiomyocyte enhancer factor 2, and then regulate cellular gene transcription and protein synthesis, leading to cardiomyocyte enlargement and fibroblast proliferation in cardiac tissues $(40,41)$. Although the role of p38 in cardiac hypertrophy remains largely elusive and controversial $(42,43)$, ERK signaling is generally accepted to have a role in this pathology. The ERK1/2 cascade was observed in hypertrophic and failing mammalian hearts, while deletion of ERK (ERK1 ${ }^{-/-}$and ERK2 ${ }^{+/}$) did not cause any obvious reduction in the hypertrophic response to various stimuli $(44,45)$. These results indicate that ERK1/2 signaling is pro-hypertrophic, but is not indispensable for the process of cardiac hypertrophy, and may explain why cells treated by HMGB1 alone did not exhibit any hypertrophic phenotype. In addition, in the present study, it was observed that HMGB1 stimulation obviously enhanced the levels of p-JAK2 and p-STAT3 in cardiomyocytes, indicating that HMGB1 has an effect on JAK2/STAT3 signaling; however, this pathway may not participate in the process of HMGB1-enhanced cardiomyocyte hypertrophy induced by mechanical stress. Another reasonable explanation for these results is that the signaling pathways involved in cardiac hypertrophy including MAPKs and JAK/STAT are highly complex with multiple cross-talk, and that activation of one protein or one signaling pathway may not be sufficient to induce a phenotype change.

HMGB1 is involved in cell hypertrophy in neonatal rat cardiomyocytes and this process is closely linked to calcineurin (31). Neonatal rat cardiomyocytes subjected to mechanical stretch develop hypertrophy and increased intracellular and extracellular HMGB1 expression in vitro, and the latter effect is abolished by fenofibrate, an inhibitor of cardiac hypertrophy (46). Furthermore, inhibition of HMGB1 release, or promotion of nuclear translocation of HMGB1, has also been reported to attenuate cardiac hypertrophy (47), which supports that HMGB1 may have dual functions in the context of cardiac hypertrophy depending on its subcellular localization. Likewise, a previous study by our group has indicated that mechanical stress increased the expression and release of HMGB1 in cultured cardiomyocytes (8), suggesting that mechanical stress activates HMGB1 and promotes its transfer to extracellular sites and its function as a pro-hypertrophic factor.

RAGE is a transmembrane receptor that recognizes and combines with a variety of ligands, and RAGE/MAPK/NF- $\kappa$ B signaling exerts an influence on multiple processes, including cell activation, proliferation and migration $(48,49)$. RAGE is involved in a variety of pathologies mediated by HMGB1, and this axis may represent a potential target for cardiac hypertrophy induced by HMGB1 (50). Kim et al (51) reported that HMGB1 induced the activity of fibroblasts via RAGE/MAPK and NF- $\kappa \mathrm{B}$ signaling in keloid scar formation, while Andrassy et al (15) demonstrated the pro-inflammatory activity of HMGB1 depended on RAGE activation, since $\mathrm{RAGE}^{-/}$mice were protected from $\mathrm{I} / \mathrm{R}$ injury even after administration of HMGB1. In addition, previous studies have revealed that activation of TLR-4 promoted cardiac hypertrophy, while genetic or pharmacological inhibition of TLR-4 had the opposite effect (52-54). In the present study, it was indicated that RAGE blockade significantly attenuated the HMGB1-mediated activation of ERK1/2 in cardiomyocytes, but had no effect on the JAK2/STAT3 pathway. Blocking the TLR-4 receptor appeared to exert no effect on either MAPK or JAK2/STAT3 signaling, suggesting a regulatory role of RAGE to activate ERK1/2 following extracellular HMGB1 stimulation. In the present study, anti-RAGE or anti-TLR-4 neutralizing antibodies were used in cells treated with HMGB1 alone, but their effect on the combined treatment of HMGB1 and mechanical stress was 
not examined. However, since mechanical stress is a powerful stimulation to cultured cardiomyocytes and RAGE or TLR-4 are only two of the receptors of HMGB1, the role of RAGE or TLR-4 in mediating HMGB1-induced activation of ERK1/2 and JAK2/STAT3 would be difficult to be observed under mechanical stress. Based on the current findings that RAGE was involved in the function of HMGB1, further studies will be performed in the future to explore the roles of these receptors under mechanical stress. In addition, cell function or damage will be also evaluated in future studies, in order to fully explore the mechanisms of HMGB1 in cardiomyocyte impairment.

The present study demonstrated that HMGB1 stimulation enhanced mechanical stretch-induced cardiomyocyte hypertrophy and ERK activation. Furthermore, it was observed that blocking of RAGE attenuated the effect of HMGB1 to activate ERK, while blocking of TLR-4 was ineffective. The present results indicated that the pro-hypertrophic effect of HMGB1 under mechanical stress may depend, at least partially, on RAGE/ERK signaling. In addition, the JAK/STAT pathway, which may also be activated by mechanical stress and HMGB1, appears to not be regulated by RAGE or TLR-4 receptors. Further investigation of these interactions in future studies may reveal the roles of HMGB1 activation in cardiac hypertrophy in more detail.

\section{Acknowledgements}

Not applicable.

\section{Funding}

This study was supported by the National Science Foundation of China (grant. nos. 81400193, 81670355, 81671934 and 81521001).

\section{Availability of data and materials}

The datasets used and/or analyzed during the current study are available from the corresponding author on reasonable request.

\section{Authors' contributions}

HJ, LZ and JG contributed to the conception and design of the study. LZ, XY and GJ performed experiments and data analysis. YY, JW, YS, AS and YZ contributed to the statistical analysis and interpretation of the results. LZ, XY and GJ wrote the manuscript. HJ, YY, JW, YS, AS, YZ and JG were involved in the critical revision of the manuscript. All authors discussed the final results and approved the final manuscript.

\section{Ethics approval and informed consent to participate}

The experiment protocols were approved by the Institutional Animal Care and Use Committee of Fudan University (Shanghai, China).

\section{Patient consent for publication}

Not applicable.

\section{Competing interests}

The authors declare that they have no competing interests.

\section{References}

1. Tham YK, Bernardo BC, Ooi JY, Weeks KL and McMullen JR: Pathophysiology of cardiac hypertrophy and heart failure: Signaling pathways and novel therapeutic targets. Arch Toxicol 89: 1401-1438, 2015.

2. Kwon HK, Jeong H, Hwang D and Park ZY: Comparative proteomic analysis of mouse models of pathological and physiological cardiac hypertrophy, with selection of biomarkers of pathological hypertrophy by integrative Proteogenomics. Biochim Biophys Acta Proteins Proteom 30118-30123, Jul 23, 2018 [Epub ahead of print].

3. Higashikuni Y, Tanaka K, Kato M, Nureki O, Hirata Y, Nagai R, Komuro I and Sata M: Toll-like receptor-2 mediates adaptive cardiac hypertrophy in response to pressure overload through interleukin-lbeta upregulation via nuclear factor kappaB activation. J Am Heart Assoc 2: e000267, 2013.

4. Verma SK, Krishnamurthy P, Barefield D, Singh N, Gupta R, Lambers E, Thal M, Mackie A, Hoxha E, Ramirez V, et al: Interleukin-10 treatment attenuates pressure overload-induced hypertrophic remodeling and improves heart function via signal transducers and activators of transcription 3-dependent inhibition of nuclear factor-kappaB. Circulation 126: 418-429, 2012.

5. Sun M, Chen M, Dawood F, Zurawska U, Li JY, Parker T, Kassiri Z, Kirshenbaum LA, Arnold M, Khokha R and Liu PP: Tumor necrosis factor-alpha mediates cardiac remodeling and ventricular dysfunction after pressure overload state. Circulation 115: 1398-1407, 2007.

6. Andersson U and Tracey KJ: HMGB1 is a therapeutic target for sterile inflammation and infection. Annu Rev Immunol 29: 139-162, 2011.

7. Kang R, Chen R, Zhang Q, Hou W, Wu S, Cao L, Huang J, Yu Y, Fan XG, Yan Z, et al: HMGB1 in health and disease. Mol Aspects Med 40: 1-116, 2014.

8. Zhang L, Liu M, Jiang H, Yu Y, Yu P, Tong R, Wu J, Zhang S, Yao K, Zou Y and Ge J: Extracellular high-mobility group box 1 mediates pressure overload-induced cardiac hypertrophy and heart failure. J Cell Mol Med 20: 459-470, 2016.

9. Nakamura M and Sadoshima J: Mechanisms of physiological and pathological cardiac hypertrophy. Nat Rev Cardiol 15: 387-407, 2018.

10. Shimizu I and Minamino T: Physiological and pathological cardiac hypertrophy. J Mol Cell Cardiol 97: 245-262, 2016.

11. Liu R and Molkentin JD: Regulation of cardiac hypertrophy and remodeling through the dual-specificity MAPK phosphatases (DUSPs). J Mol Cell Cardiol 101: 44-49, 2016.

12. Ruppert C, Deiss K, Herrmann S, Vidal M, Oezkur M, Gorski A Weidemann F, Lohse MJ and Lorenz K: Interference with ERK(Thr188) phosphorylation impairs pathological but not physiological cardiac hypertrophy. Proc Natl Acad Sci USA 110: 7440-7445, 2013.

13. Heineke J and Molkentin JD: Regulation of cardiac hypertrophy by intracellular signalling pathways. Nat Rev Mol Cell Biol 7: 589-600, 2006.

14. Yuan L, Qiu L, Ye Y, Wu J, Wang S, Wang X, Zhou N and Zou Y: Heat-shock transcription factor 1 is critically involved in the ischaemia-induced cardiac hypertrophy via JAK2/STAT3 pathway. J Cell Mol Med 22: 4292-4303, 2018.

15. Andrassy M, Volz HC, Igwe JC, Funke B, Eichberger SN, Kaya Z, Buss S, Autschbach F, Pleger ST, Lukic IK, et al: High-mobility group box-1 in ischemia-reperfusion injury of the heart. Circulation 117: 3216-3226, 2008.

16. Mir SA, Chatterjee A, Mitra A, Pathak K, Mahata SK and Sarkar S: Inhibition of signal transducer and activator of transcription 3 (STAT3) attenuates interleukin-6 (IL-6)-induced collagen synthesis and resultant hypertrophy in rat heart. J Biol Chem 287: 2666-2677, 2012.

17. Hou T, Tieu BC, Ray S, Recinos Iii A, Cui R, Tilton RG and Brasier AR: Roles of IL-6-gp130 signaling in vascular inflammation. Curr Cardiol Rev 4: 179-192, 2008.

18. Fritz G: RAGE: A single receptor fits multiple ligands. Trends Biochem Sci 36: 625-632, 2011. 
19. Herzog C, Lorenz A, Gillmann HJ, Chowdhury A, Larmann J, Harendza T, Echtermeyer F, Müller M, Schmitz M, Stypmann J, et al: Thrombomodulin's lectin-like domain reduces myocardial damage by interfering with HMGB1-mediated TLR2 signalling. Cardiovasc Res 101: 400-410, 2014.

20. Narayanan KB and Park HH: Toll/interleukin-1 receptor (TIR) domain-mediated cellular signaling pathways. Apoptosis 20: 196-209, 2015

21. Orliaguet G, Vivien B, Langeron O, Bouhemad B, Coriat P and Riou B: Minimum alveolar concentration of volatile anesthetics in rats during postnatal maturation. Anesthesiology 95: 734-739, 2001.

22. Tsukamoto A, Konishi Y, Kawakami T, Koibuchi C, Sato R, Kanai $\mathrm{E}$ and Inomata T: Pharmacological properties of various anesthetic protocols in 10-day-old neonatal rats. Exp Anim 66: 397-404, 2017.

23. Zhang L, Jiang H, Gao X, Zou Y, Liu M, Liang Y, Yu Y, Zhu W, Chen $\mathrm{H}$ and Ge J: Heat shock transcription factor-1 inhibits $\mathrm{H} 2 \mathrm{O} 2$-induced apoptosis via down-regulation of reactive oxygen species in cardiac myocytes. Mol Cell Biochem 347: 21-28, 2011

24. Ehler E, Moore-Morris T and Lange S: Isolation and culture of neonatal mouse cardiomyocytes. J Vis Exp 2013.

25. Zhou N, Li L, Wu J, Gong H, Niu Y, Sun A, Ge J and Zou Y: Mechanical stress-evoked but angiotensin II-independent activation of angiotensin II type 1 receptor induces cardiac hypertrophy through calcineurin pathway. Biochem Biophys Res Commun 397: 263-269, 2010.

26. Sadoshima J, Jahn L, Takahashi T, Kulik TJ and Izumo S: Molecular characterization of the stretch-induced adaptation of cultured cardiac cells. An in vitro model of load-induced cardiac hypertrophy. J Biol Chem 267: 10551-10560, 1992.

27. Zou Y, Akazawa H, Qin Y, Sano M, Takano H, Minamino T, Makita N, Iwanaga K, Zhu W, Kudoh S, et al: Mechanical stress activates angiotensin II type 1 receptor without the involvement of angiotensin II. Nat Cell Biol 6: 499-506, 2004.

28. Kokkola R, Andersson A, Mullins G, Ostberg T, Treutiger CJ, Arnold B, Nawroth P, Andersson U, Harris RA and Harris HE: RAGE is the major receptor for the proinflammatory activity of HMGB1 in rodent macrophages. Scand J Immunol 61: 1-9, 2005

29. Tzeng HP, Fan J, Vallejo JG, Dong JW, Chen X, Houser SR and Mann DL: Negative inotropic effects of high-mobility group box 1 protein in isolated contracting cardiac myocytes. Am J Physiol Heart Circ Physiol 294: H1490-H1496, 2008.

30. Beetz N, Rommel C, Schnick T, Neumann E, Lother A, Monroy-Ordonez EB, Zeeb M, Preissl S, Gilsbach R, Melchior-Becker A, et al: Ablation of biglycan attenuates cardiac hypertrophy and fibrosis after left ventricular pressure overload J Mol Cell Cardiol 101: 145-155, 2016.

31. Su FF, Shi MQ, Guo WG, Liu XT, Wang HT, Lu ZF and Zheng QS High-mobility group box 1 induces calcineurin-mediated cell hypertrophy in neonatal rat ventricular myocytes. Mediators Inflamm 2012: 805149, 2012

32. Zhao L, Cheng G, Jin R, Afzal MR, Samanta A, Xuan YT, Girgis M, Elias HK, Zhu Y, Davani A, et al: Deletion of Interleukin-6 Attenuates pressure overload-induced left ventricular hypertrophy and dysfunction. Circ Res 118: 1918-1929, 2016

33. Shyu KG, Wang BW, Wu GJ, Lin CM and Chang H: Mechanical stretch via transforming growth factor-betal activates microRNA208a to regulate endoglin expression in cultured rat cardiac myoblasts. Eur J Heart Fail 15: 36-45, 2013.

34. Chua S, Lee FY, Chiang HJ, Chen KH, Lu HI, Chen YT, Yang CC, Lin KC, Chen YL, Kao GS, et al: The cardioprotective effect of melatonin and exendin-4 treatment in a rat model of cardiorenal syndrome. J Pineal Res 61: 438-456, 2016.

35. Hou M, Gu HC, Wang HH, Liu XM, Zhou CL, Yang Q, Jiang ZR, Lin J, Wu YM, Wu YT, et al: Prenatal exposure to testosterone induces cardiac hypertrophy in adult female rats through enhanced Pkcdelta expression in cardiac myocytes. J Mol Cell Cardiol 128: 1-10, 2019.

36. Mohan N, Kumar V, Kandala DT, Kartha CC and Laishram RS A Splicing-independent function of RBM10 controls specific 3 UTR processing to regulate cardiac hypertrophy. Cell Rep 24 3539-3553, 2018

37. Cheng KC, Chang WT, Kuo FY, Chen ZC, Li Y and Cheng JT: TGR5 activation ameliorates hyperglycemia-induced cardiac hypertrophy in H9c2 cells. Sci Rep 9: 3633, 2019.
38. Schirone L, Forte M, Palmerio S, Yee D, Nocella C, Angelini F, Pagano F, Schiavon S, Bordin A, Carrizzo A, et al: A review of the molecular mechanisms underlying the development and progression of cardiac remodeling. Oxid Med Cell Longev 2017: 3920195, 2017.

39. Komuro I: Molecular mechanism of cardiac hypertrophy and development. Jpn Circ J 65: 353-358, 2001.

40. Kacimi R and Gerdes AM: Alterations in G protein and MAP kinase signaling pathways during cardiac remodeling in hypertension and heart failure. Hypertension 41: 968-977, 2003.

41. Gutkind JS and Offermanns S: A new G(q)-initiated MAPK signaling pathway in the heart. Dev Cell 16: 163-164, 2009.

42. Reyes DRA, Gomes MJ, Rosa CM, Pagan LU, Zanati SG, Damatto RL, Rodrigues EA, Carvalho RF, Fernandes AAH, Martinez PF, et al: Exercise during transition from compensated left ventricular hypertrophy to heart failure in aortic stenosis rats. J Cell Mol Med 23: 1235-1245, 2019.

43. Kojonazarov B, Novoyatleva T, Boehm M, Happe C, Sibinska Z, Tian X, Sajjad A, Luitel H, Kriechling P, Posern G, et al: p38 MAPK inhibition improves heart function in pressure-loaded right ventricular hypertrophy. Am J Respir Cell Mol Biol 57: 603-614, 2017.

44. Mutlak M and Kehat I: Extracellular signal-regulated kinases 1/2 as regulators of cardiac hypertrophy. Front Pharmacol 6: 149, 2015.

45. Purcell NH, Wilkins BJ, York A, Saba-El-Leil MK, Meloche S, Robbins $\mathrm{J}$ and Molkentin JD: Genetic inhibition of cardiac ERK1/2 promotes stress-induced apoptosis and heart failure but has no effect on hypertrophy in vivo. Proc Natl Acad Sci USA 104: 14074-14079, 2007

46. Jia Z, Xue R, Liu G, Li L, Yang J, Pi G, Ma S and Kan Q: HMGB1 is involved in the protective effect of the PPAR $\alpha$ agonist fenofibrate against cardiac hypertrophy. PPAR Res 2014: 541394, 2014.

47. Funayama A, Shishido T, Netsu S, Narumi T, Kadowaki S, Takahashi H, Miyamoto T, Watanabe T, Woo CH, Abe J, et al: Cardiac nuclear high mobility group box 1 prevents the development of cardiac hypertrophy and heart failure. Cardiovase Res 99: 657-664, 2013.

48. Sessa L, Gatti E, Zeni F, Antonelli A, Catucci A, Koch M, Pompilio G, Fritz G, Raucci A and Bianchi ME: The receptor for advanced glycation end-products (RAGE) is only present in mammals, and belongs to a family of cell adhesion molecules (CAMs). PLoS One 9: e86903, 2014

49. Nonaka K, Kajiura Y, Bando M, Sakamoto E, Inagaki Y, Lew JH, Naruishi K, Ikuta T, Yoshida K, Kobayashi T, et al: Advanced glycation end-products increase IL-6 and ICAM-1 expression via RAGE, MAPK and NF-kappaB pathways in human gingival fibroblasts. J Periodontal Res 53: 334-344, 2018.

50. Wu CZ, Zheng JJ, Bai YH, Xia P, Zhang HC and Guo Y: HMGB1/RAGE axis mediates the apoptosis, invasion, autophagy, and angiogenesis of the renal cell carcinoma. Onco Targets Ther 11: 4501-4510, 2018

51. Kim J, Park JC, Lee MH, Yang CE, Lee JH and Lee WJ: High-mobility group Box 1 mediates fibroblast activity via RAGE-MAPK and NF-kappaB signaling in keloid scar formation. Int J Mol Sci 19: E76, 2017.

52. Ha T, Li Y, Hua F, Ma J, Gao X, Kelley J, Zhao A, Haddad GE, Williams DL, William Browder I, et al: Reduced cardiac hypertrophy in toll-like receptor 4-deficient mice following pressure overload. Cardiovasc Res 68: 224-234, 2005.

53. Ehrentraut H, Weber C, Ehrentraut S, Schwederski M, Boehm O, Knuefermann P, Meyer R and Baumgarten G: The toll-like receptor 4-antagonist eritoran reduces murine cardiac hypertrophy. Eur J Heart Fail 13: 602-610, 2011.

54. Jiang DS, Zhang XF, Gao L, Zong J, Zhou H, Liu Y, Zhang Y, Bian ZY, Zhu LH, Fan GC, et al: Signal regulatory protein-alpha protects against cardiac hypertrophy via the disruption of toll-like receptor 4 signaling. Hypertension 63: 96-104, 2014.

This work is licensed under a Creative Commons Attribution-NonCommercial-NoDerivatives 4.0 International (CC BY-NC-ND 4.0) License. 